\title{
Investigation of Control Model in a New Series Hybrid Hydraulic/Electric System for Heavy Vehicles Based on Energy Efficiency
}

\author{
Soroosh Mahmoodi, ${ }^{1,2}$ Hu Guoqing, ${ }^{1,3}$ and Mehrdad Nouri Khajavi ${ }^{2,4}$ \\ ${ }^{1}$ Mechanical \& Electrical Department, Xiamen University, Xiamen, Fujian, China \\ ${ }^{2}$ Mechanical Department, Islamic Azad University, Takestan, Iran \\ ${ }^{3}$ South China University of Technology, Guangzhou, Guangdong, China \\ ${ }^{4}$ Shahid Rajaee Teacher Training University, Tehran, Iran
}

Correspondence should be addressed to Soroosh Mahmoodi; soroosh.mahmoodi@yahoo.com

Received 24 May 2015; Revised 22 August 2015; Accepted 30 August 2015

Academic Editor: Herbert Ho-Ching Iu

Copyright (C) 2016 Soroosh Mahmoodi et al. This is an open access article distributed under the Creative Commons Attribution License, which permits unrestricted use, distribution, and reproduction in any medium, provided the original work is properly cited.

\begin{abstract}
An interesting model which was able to recuperate and reuse braking energy was investigated. It was named series hybrid hydraulic/electric system (SHHES). The innovated model was presented for heavy hybrid vehicles to overcome the existing drawbacks of single energy storage sources. The novelty of this paper was investigation of a new series hybrid vehicle with triple sources, combustion engine, electric motor, and hydraulic sources. It was simulated with MATLAB-Simulink and different operational mode of control system was investigated. The aim was to improve the efficiency of the energy-loading components in the power train system and the transmission system independently. The ability to store and reuse the kinetic energy was added to the system to prevent energy wasting while the vehicle was braking. Control models were also investigated to realize suitable control algorithms to offer the best efficiency in system components for different vehicle conditions. The torque control strategy based on fuzzy logic controller was proposed to achieve better vehicle performance while the fuel consumption was minimized. The results implied efficient storage and usage in the transmission system. A small vehicle model experimentally verified the simulation results.
\end{abstract}

\section{Introduction}

Refuse trucks or city buses as the heavy vehicles have important duties in civilized cities. According to the heavy vehicles fuel consumption and their typical stop and start driving cycles, their fuel consumption has influence on cities economics.

However, the fuel saving strongly depends on the driving performance and operational modes; operation time also has an important role in transportation cost. Less operation time and more transportation will benefit the transportation companies. Drivers try more acceleration and deceleration to save the time during the driving cycle. The aggressive drivers need more acceleration power and should waste more energy during braking process. With the rising concern in the global energy management and the environment pollution, energy saving in automobiles, especially heavy city vehicles, is one of the most important energy topics. Research for improving fuel efficiency and reducing emissions without sacrificing vehicle performance, safety, reliability, and other conventional vehicle attributes has made the hybrid technology one of the most important developments for the automotive industries [1]. Battery and fuel battery technology have suitable high energy density, but the relatively lower power density makes them only marginal in recovering the kinetic energy during braking process. Supercapacitors have higher power density and more lifetime than the batteries, but the challenges of supercapacitors are their expensive prices [2]. Hydraulic accumulator has higher power density and energy conversion efficiency than the batteries and supercapacitors, which is well suited for storing the high power energies during the braking in a short time for heavy vehicles [3], 


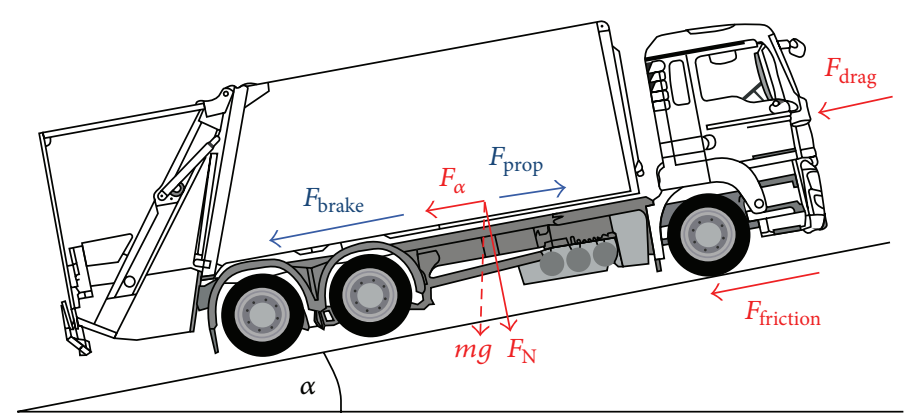

FIgURE 1: Forces acting on a refuse truck.

TABLE 1: Hydraulic accumulators versus electric batteries.

\begin{tabular}{lcc}
\hline $\begin{array}{l}\text { Energy recovery } \\
\text { performance }\end{array}$ & $\begin{array}{c}\text { Hydraulic } \\
\text { accumulator }\end{array}$ & $\begin{array}{c}\text { Electric battery } \\
\text { Li-ion }\end{array}$ \\
\hline $\begin{array}{l}\text { Power density } \\
\text { Energy density }\end{array}$ & $5 \mathrm{KW} / \mathrm{Kg}$ & $0.5 \mathrm{KW} / \mathrm{Kg}$ \\
$\begin{array}{l}\text { Round-trip } \\
\text { efficiency }\end{array}$ & $94 \%$ & $150 \mathrm{KJ} / \mathrm{Kg}$ \\
\hline
\end{tabular}

but the lower energy density of the hydraulic accumulators makes them difficult as the only energy storage source to design the energy control strategy for minimizing the fuel consumption $[4,5]$. It is also realized that a single energy storage source cannot satisfy both the peak power and energy density requirements in the heavy vehicles [6]. As the results it could be implied that the benefits of using electric batteries were their higher energy density, which make them possible to develop full electric light vehicles; on the other hand, the benefits of the hydraulic accumulators are their high power density and high round-trip efficiency which make them suitable for heavy hybrid vehicles; Table 1 shows a comparative value between hydraulic accumulators and electric batteries.

Recently, the simultaneous use of multiple energy storage sources with different characters is a challenging solution for heavy hybrid vehicles. Both high energy density sources and the high power density sources can be exploited simultaneously [7].

Some researches were investigated for energy control strategies in heavy hybrid vehicles that deal with heuristic control techniques such as logic threshold, fuzzy logic, and others devoted to optimizing the power split between the hybrid energy sources [8], but the discussion of combination in hydraulic sources and electric sources is also a new topics.

Using methods to improve the overall system efficiency was the targets of using hybrid technology which could be classified as follows efficient usage of the primary power source, efficient transformation of fuel energy to motion energy, and the efficient recovering and reuse of the braking energy.

Controllability, robustness, reliability, and life cycle expenses were also some important requirements [9].

\section{Mathematic of Vehicle Dynamic}

2.1. Vehicle Dynamics Formulation. Vehicle dynamic equations [10] are given through the well-known equations (1)-(6) as visible in Figure 1:

$$
J \alpha_{\text {wheel }}=T_{\text {prop }}-T_{\text {ext }} .
$$

According to the configuration of the proposed hybrid power train in Figure 3, the values of the resulting inertia $J$ and the propulsion torque $T_{\text {prop }}$ depend on the control operation mode which is the case of the magnetic clutch operation, and the overall moment of inertia is given by

$$
J=m r^{2}+J_{\text {fix }}+J_{\text {elec }}+J_{\text {hyd }} .
$$

$J_{\text {elec }}$ is the moment of inertia due to the rotating masses components in the electric motor/generator $2, J_{\text {fix }}$ is the moment of inertia due to all parts of power train, and $J_{\text {hyd }}$ is the hydraulic variable displacement pump/motor components inertia which is dependent on the magnetic clutch state and it can be coupled to the transmission system through the magnetic clutch:

$$
\begin{aligned}
\alpha_{\text {wheel }} & =\frac{\dot{v}}{r}, \\
T_{\text {ext }} & =F_{\text {ext }} \cdot r=\left(F_{\text {drag }}+F_{\text {roll }}+F_{\text {slop }}\right) \cdot r, \\
F_{\text {drag }} & =\frac{1}{2}\left(\rho_{L} c_{w} A V^{2}\right), \\
F_{\text {roll }} & =m g f_{r} \cos (\alpha), \\
F_{\text {slop }} & =m g \sin (\alpha) .
\end{aligned}
$$

Equation (4) describes $T_{\text {prop }}$ that defines the propulsion torque produced by the propulsion system generators:

$$
T_{\text {prop }}=\left(T_{\text {elec }}+T_{\text {hyd }}\right) \mu_{\text {diff }}+T_{\text {brake }}
$$

$\mu_{\text {diff }}$ was the torque conversion ratio of the vehicle differential system.

Two different configurations could be obtained from the magnetic clutch state for the propulsion and the braking operations: 


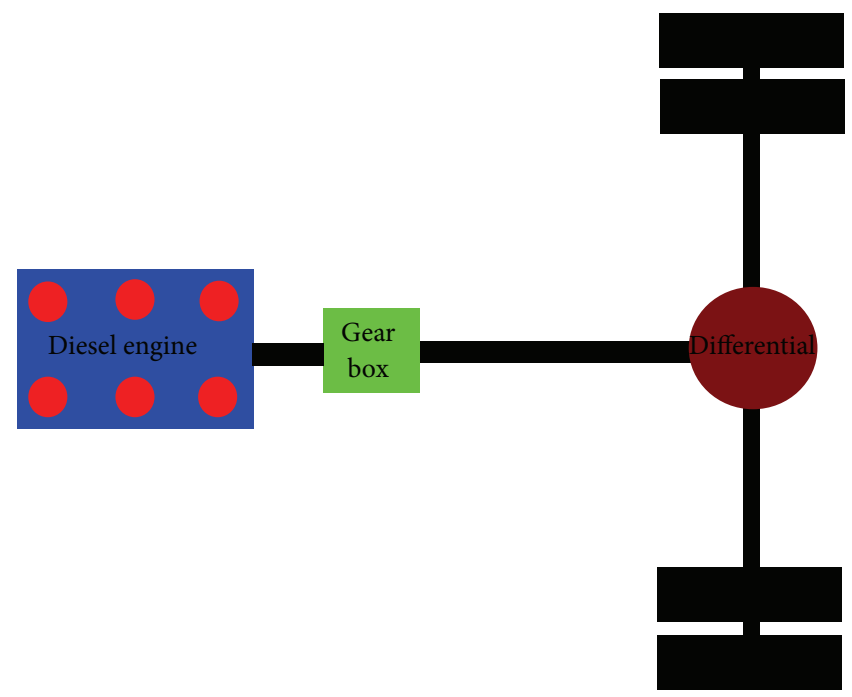

FIgURE 2: Traditional transmission system.

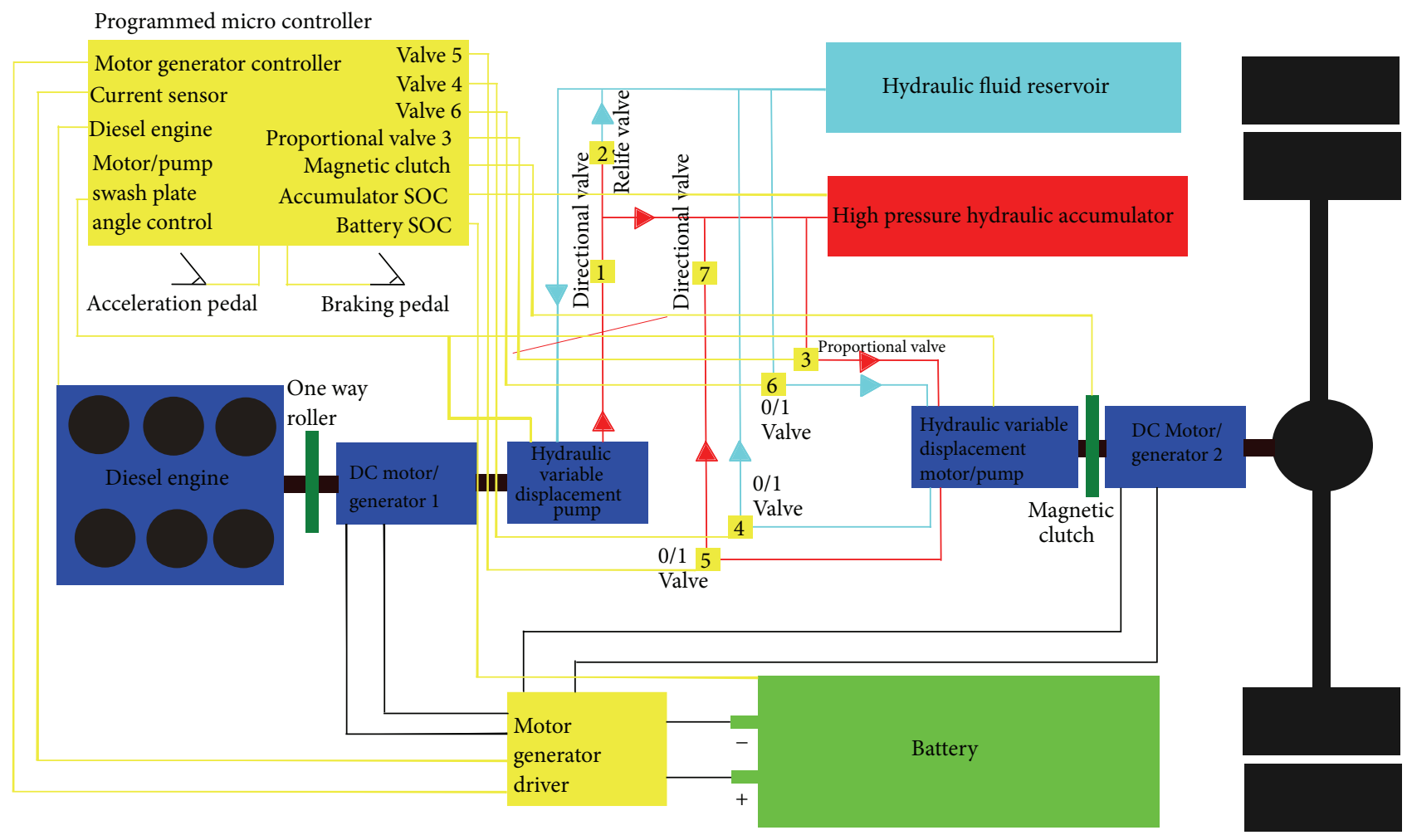

FIGURE 3: Schematic system of series hybrid hydraulic/electric system.

(1) Both hydraulic and electric power generation lines were coupled to the differential:

$$
T_{\text {prop }}=\left(T_{\text {elec }}+T_{\text {hyd }}\right) \mu_{\text {diff }}+T_{\text {brake }} .
$$

(2) Hydraulic system was decoupled from electric motor/ generator 2 and the differential:

$$
T_{\text {prop }}=T_{\text {elec }} \cdot \mu_{\text {diff }}+T_{\text {brake }} .
$$

Figure 2 shows the traditional transmission system which would be compared with the proposed hybrid system.

2.2. Base Line Energy Management. The hybrid vehicle's overall propulsion torque in (5) needs to be distributed among the electric motor/generator 2 and the axial piston variable hydraulic motor/pump which were connected to the differential. In addition, the operating constraints on the power train components need to be involved in the accounts. This 
could be expressed with the base line energy management

strategy given by

$$
\begin{aligned}
& T_{\text {hyd }}= \begin{cases}\min \left(\max \left(\frac{T_{\text {prop }}}{\mu_{h} \cdot \mu_{\text {diff }}}, \min \right), T_{\text {hyd }}, \max \right), & \text { if } 0<\mathrm{SOC}_{\text {accumulator }}<1 \\
0 & \text { Otherwise, }\end{cases} \\
& T_{\text {elec }}= \begin{cases}\min \left(\max \left(\frac{T_{\text {prop }}}{\mu_{\text {diff }}}, T_{\text {elec }}, \min \right), T_{\text {elec }}, \max \right), & \text { if } 0<\mathrm{SOC}_{\text {battery }}<1 \\
0 & \text { Otherwise, }\end{cases} \\
& T_{\text {brake }}=\min \left(T_{\text {prop }}-\mu_{\text {diff }}\left(T_{\text {elec }}+\mu_{h} \cdot T_{\text {hyd }}\right), 0\right) .
\end{aligned}
$$

Detailed information on the derivation of some parts of this base line energy management could be found in $[11,12]$.

Note that exclusive electric propulsion $\left(T_{\text {hyd }}=0\right)$ was operated when the required torque could be solely provided by the electric unit. It would happen while the vehicle was not in hill climbing or hard acceleration mode. Within the performed simulation and during vehicle test the base line strategy equations (7) are used as the reference of fuel saving analysis.

\section{Proposed Hybrid Hydraulic/Electric Model and System Components}

The power generation unit system contains a 6-cylinder diesel engine, DC brushless motor/generator 1, a hydraulic variable displacement axial piston compensated pump, and a one-way roller bearing. They were connected to each other through the one-way roller bearing for storing electric energy in the battery and pressurized hydraulic energy in the accumulator. If the diesel engine was shut down and if the accumulator was empty of fluid charge, the DC motor/generator 1 would tank the accumulator. The one-way roller bearing caused the fact that the DC motor would not need to rotate the diesel engine and would cause the prevention of energy loss due to the diesel engine parts frictions. The proposed system was shown in Figure 3. The propulsion unit system contains a hydraulic high pressure accumulator, battery pack, hydraulic valves \{directional valves (numbers 1 and 7), 0/1 valves (numbers 4,5, and 6), proportional valve (number 3 ), and relief valve (number 2)\}, a low pressure hydraulic reservoir, a variable displacement hydraulic motor/pump, DC motor/generator 2, a magnetic clutch, and a differential. The hydraulic variable displacement motor/pump was connected to the DC motor/generator 2 and the differential via a magnetic clutch. They could transfer the power to the wheels and vice versa receive the motion power from the wheels in the braking process. Accumulator and battery pack were used as the storage energy unit. The control system contains an AVR microcontroller (Atmega 32). Microcontroller (AVR) was programmed to control the valves, motor/generator driver, magnetic clutch state, and hydraulic pump/motor swash plate angles. The hydraulic valves could control the fluid flow paths and overload pressure safety. Red, blue, black, and yellow lines in order indicate high pressure, low pressure, and electric and control lines.

\section{Energy Loading and Recovering Component Efficiency}

The power generation unit and the propulsion system efficiency depended on the number of series components and the efficiency of each component which were connected to the system:

$$
\begin{aligned}
\eta_{\text {power generator }}= & \eta_{\text {diesel engine }}+\eta_{\text {motor/generator } 1}+\eta_{\text {battery }} \\
& +\eta_{\text {variable pump }}+\eta_{\text {accumulator }} \\
\eta_{\text {propulsion }}= & \eta_{\text {variable hydraulic motor/pump }} \\
& +\eta_{\text {motor/generator 2 }}+\eta_{\text {differential }}
\end{aligned}
$$

4.1. Diesel Engine. To minimize the fuel consumption, first it was needed to adjust the diesel engine speed according to the demanded loading torque in optimal region. The diesel engine rotation speed adjustment was independent of the vehicle speed which was the most useful parameter of series hybrid vehicles. Figure 4 shows the diesel engine characteristic in different torque-speed regions [13].

Then it was possible to optimize the variable displacement pump by controlling the swash plate angle in efficient region.

Figure 4 also shows "overspeed" of the diesel engine rotation speed. It could drastically increase the fuel consumption and reduce engine efficiency.

4.2. Dc Motor/Generator and Battery. Mechanical power output indicates the generation of torque and speed with a correction factor for electric motor units:

$$
\eta_{\text {Electric motor }}=\frac{\text { Mechanical power output }}{\text { The electrical power input }} .
$$

Figure 5 which was constructed by Micro motion solutionFaulhaber shows an electric motor characteristic curve. Motor efficiency at various points from no-load to stall torque was also shown. 


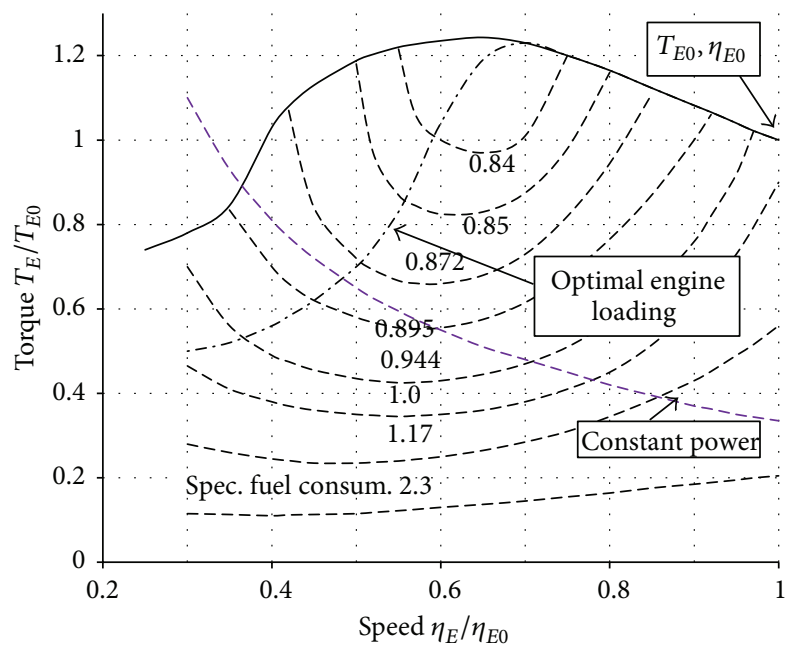

FIGURE 4: Schematic characteristic for diesel engine.

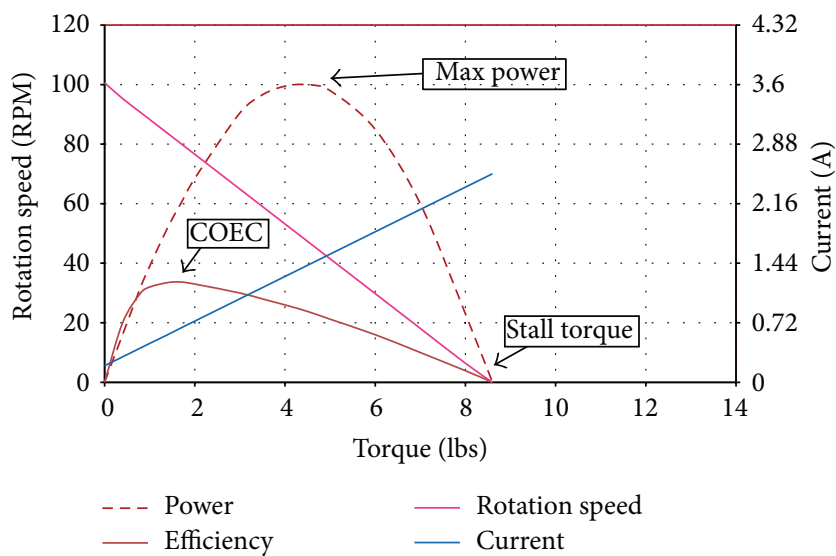

FIGURE 5: Speed, power, efficiency, and current in different torque speed.

The maximum motor efficiency occurs at about $20 \%$ of the motor stall torque and the maximum motor power occurs at approximately $50 \%$ of the stall torque, and the speed at the maximum motor power is approximately $50 \%$ of the no-load speed. For better understanding of control strategy algorithm in next sections, the research defines a factor named "Critical Optimal Electric Current (COEC)." This factor was a specific current value that would occur about $20 \%$ of the electric motor stall torque current. In COEC point the electric motor had the most efficiency; it was shown in Figure 5.

If the vehicle was in high acceleration or hill climbing, then the propulsion system should produce higher torque on the wheel axis. If the electric motor must supply all the power alone, then electric motor torque has to be increased. Figure 6 shows electric motor torque current which indicates that higher motor torque demanded higher electric current which must be supplied from electric sources or batteries.

In a full electric automotive application, if high electric motor current rates were used regularly for hard acceleration or for hill climbing, the range of the vehicle will be reduced. This is a result of battery high discharge rate which was an

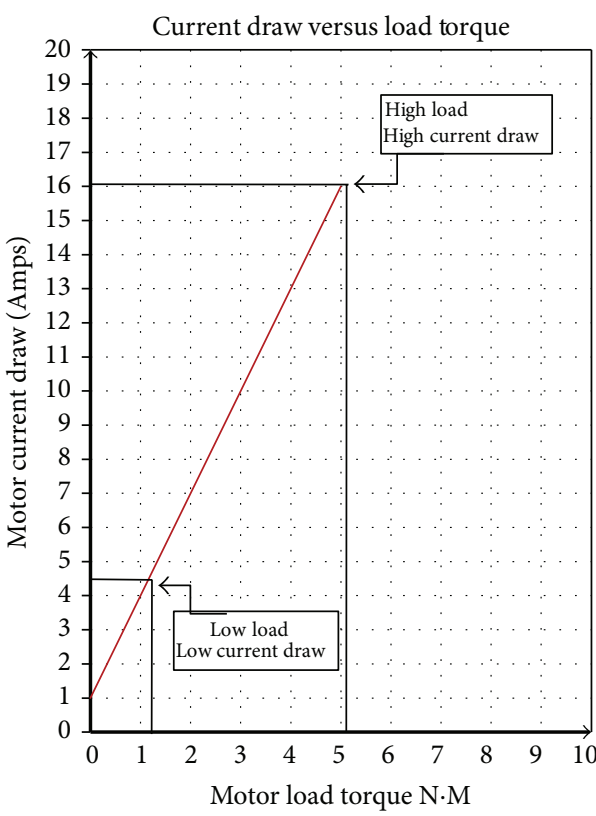

FIGURE 6: Electric motor torque-current curve.

important factor for the hybrid vehicle distance driving design.

The Peukert Equation (10) is an empirical formula which approximates how the available capacity of the batteries is spent according to the rate of discharge:

$$
C=I^{n} T
$$

where $C$ is battery theoretical capacity in Amp.Hours, $I$ is electric current, $T$ is time, and $n$ is Peukert number (a constant for the given battery).

Equation (10) shows that at higher currents demanded by the electric motor, the system should spend more battery capacity; thus, there would be less available energy in the batteries. Higher electric currents demanded by the electric motor means more losses and less available capacity in the batteries. Figure 7 is the Peukert curve. It shows the effective batteries capacity which would be reduced at higher continuous discharge rates.

4.3. Accumulator. The hydraulic accumulator contains the hydraulic fluid and highly compressed inert gas up to $300 \mathrm{Bar}$ such as nitrogen. Hydraulic accumulator is a useful device to store the energy and reuse it in hybrid vehicles [12]. Accumulators normally have high energy conversion efficiency and can be used from zero to full State Of Charge $\left(\mathrm{SOC}_{\mathrm{acc}}\right)$ in charging and discharging process without remarkable performance changes [4].

One of the other best duties of accumulators is hydraulic shocking absorption in hydraulic circuits. While the hydraulic pump or motor was faced with sudden starting of diesel engine or sudden valves opening, the hydraulic fluid shocking would be absorbed and damped by the accumulators.

It was assumed that during accumulator charging and discharging the pressure would be operated in constant 


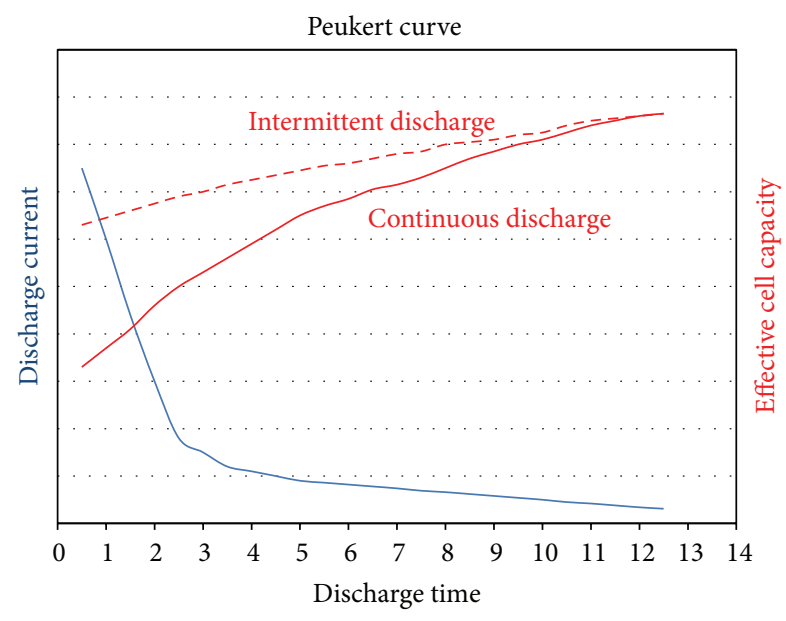

Figure 7: Peukert curve.

values. Equation (11) governs maximum recovered energy by the hydraulic accumulator:

$$
E=\int_{v_{1}}^{v_{2}} P d V=P_{2} V_{2}-P_{1} V_{1},
$$

where $P$ is the system pressure and $V$ is charging and discharging fluid volume.

\section{Control Operators with Different Drivers Behavior}

In the propulsion system the COEC value which was demanded by the electric motor/generator 1 was the control operator of the system. Different driver behavior defines different control modes in the drive line as follows:

(1) Soft acceleration or motion in nonslope road while pressing acceleration pedal demands less current than the COEC value by the electric motor/generator 1 .

(2) Hard acceleration or hill climbing while pressing acceleration pedal demands more current than the COEC value by the electric motor/generator 1 .

(3) Soft deceleration while the acceleration pedal would not be touched by the driver.

(4) Hard deceleration while the braking pedal would be touched by the driver.

(5) Emergency deceleration while the braking pedal would be pressed by the driver to stop the vehicle immediately.

In the power generation system the control operators were the battery State Of Charge $\left(\mathrm{SOC}_{\text {battery }}\right)$ and the accumulator state of charge ( $\left.\mathrm{SOC}_{\text {accumulator }}\right)$. Schematic state of charge (SOC) was shown in Figure 8. Dead band is the gap between the start and stop points in the SOC control operator.

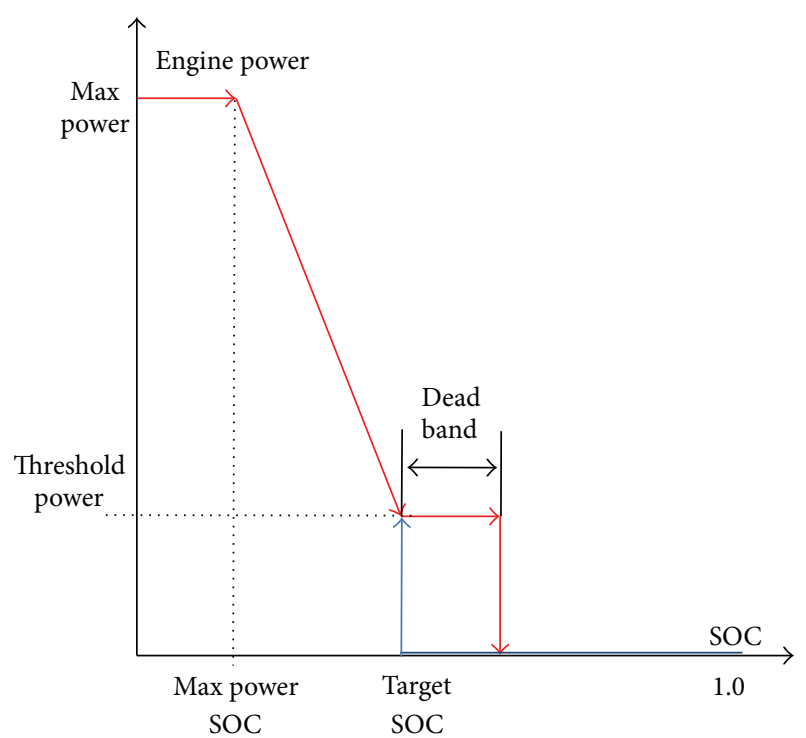

FIgURE 8: The schematic of SOC control operator.

\section{Power Generation System, Propulsion System, and Braking System Control Model}

6.1. Power Generation Control Model. There are four different control modes for the power generation unit as follows:

(1) SOC $_{\text {battery }} \leq$ Threshold power SOC battery $_{\text {. }}$

Then diesel engine $=$ start.

And motor/generator 1 switches to generator mode.

(Diesel engine was operated in optimal rotation speed, the DC motor driver would switch the DC motor/generator 1 to generator mode and would store the power in the battery, and simultaneously pressurized oil would be stored in the accumulator.)

(2) SOC $_{\text {battery }} \geq 0.9$ Max power SOC $_{\text {battery }}$.

Then diesel engine $=$ shutdown .

(3) SOC $_{\text {accumulator }} \leq$ Threshold power SOC $_{\text {accumulator }}$.

Then motor/generator 1 switches to motor mode.

And electric motor $1=$ start.

(The electric motor/generator 1 would be switched to the motor mode, motor 1 was started, and the pressurized oil would be stored in the accumulator.)

(4) $\mathrm{SOC}_{\text {accumulator }} \geq 0.9 \mathrm{Max}$ power $\mathrm{SOC}_{\text {accumulator }}$.

Then hydraulic pump swash plate angle $=0$.

(The pump swash plate angle would be set up to zero, the pump would not tank additional fluid in the accumulator, and the diesel engine by the generator 1 would just produce and store electric power in the battery.)

6.2. Propulsion System Control Model. There are two different control modes for the propulsion system as follows:

(1) Electric motor/generator 2 entrance current $\leq$ COEC. 
Then electric motor/generator 2 switches to motor mode.

And magnetic clutch $=0$ (disconnected).

And proportional valve $3=0$ (closed).

And valve $4=0$ (closed).

(The electric motor/generator 2 would be switched to motor mode and it would supply the propulsion power alone, and the hydraulic system would not be participated.)

(2) Electric motor/generator 2 entrance current > COEC.

Then electric motor/generator 2 switches to motor mode.

And magnetic clutch $=1$ (connected).

And proportional valve $3=1$ (opened).

And valve $4=1$ (opened).

(Magnetic clutch would connect the hydraulic motor to the drive line, and the hydraulic motor torque value depended on the volume of fluid flow through the proportional valve 3 and the motor swash plate angle. These values could be changed by the acceleration pedal orders. If the aggressive drivers needed more acceleration, the proportional valve 3 would be opened more while swash plate angle would be increased.)

6.3. Regenerative Braking System Control Model. There are two different control modes for the regenerative braking unit, soft and hard deceleration:

(1) Acceleration pedal $=0$ (not to be touched).

Then electric motor/generator 2 switches to generator.

And magnetic clutch $=0$ (disconnected).

And proportional valve $3=0$ (closed).

And valve $4=0$ (closed).

(This is soft deceleration while the acceleration pedal was not touched, motor/generator 2 would be switched to generator mode and will convert the vehicle motion energy to the electric power and store it in the battery, and it would cause soft speed reduction.)

(2) Braking pedal $=1$ (be touched).

Then electric motor/generator 2 switches to generator.

And magnetic clutch $=1$ (connected).

And proportional valves 3 and $4=0$ (closed).

And valves 5 and $6=1$ (opened).

(The electric generator 2 and the pump simultaneously would convert the vehicle motion energy to the electric and pressurized oil power and store it in accumulator and battery. The conventional braking system would be activated for the emergency stop by the driver demand.)
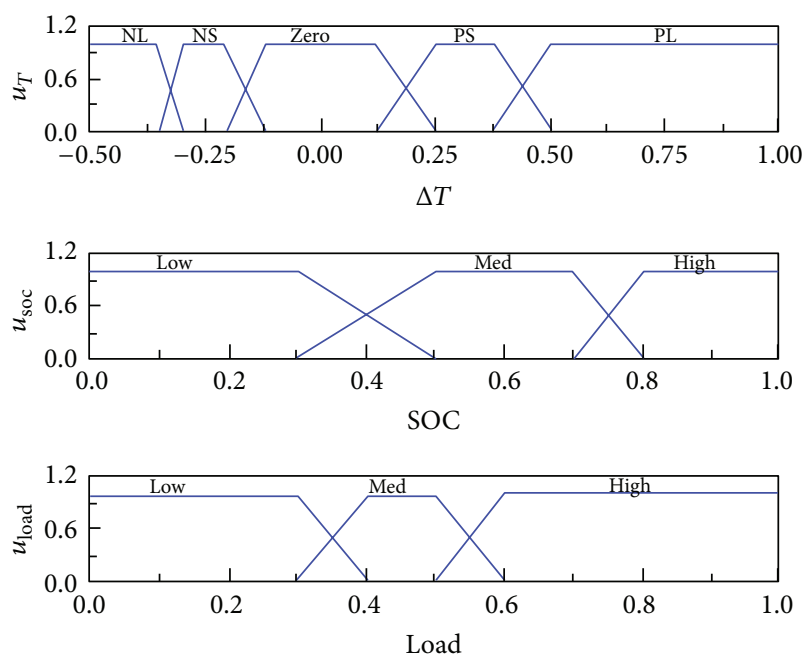

FIGURE 9: Input membership functions for the fuzzy logic controller.

\section{Fuzzy Torque Controller}

The hydraulic circuits are not efficient in higher speed and higher flow rates and have more energy losses (from Darcy Weisbach formula). The maximum electric propulsion system efficiency was operated around the COEC value. To apply efficient energy in the propulsion system the hydraulic system would help the electric system to save the battery from high discharge rates. The surplus power demanded by the driver command was compensated by the hydraulic variable displacement motor. The hydrostatic system and electric system have to be controlled simultaneously. A fuzzy logic controller was proposed to control the generated power by both sources. Membership functions were proposed by the trapezoidal-shaped functions for the load (COEC value) and the battery SOC ( $\left.\mathrm{SOC}_{\text {battery }}\right)$.

The fuzzy trapezoidal curve is a function of a vector $x$ and depends on four scalar parameters $a, b, c$, and $d$, as given by

$$
f(x ; a, b, c, d)=\max \left[\min \left(\frac{x-a}{b-a}, 1, \frac{d-x}{d-c}\right), 0\right],
$$

where the parameters $(a)$ and $(d)$ locate at the "feet" and the parameters $(b)$ and $(c)$ locate at the "shoulders." Fuzzy rules were proposed by the optimum results of many simulations. Load (COEC value) was the input function for the propulsion system and battery SOC was the input function for the power generation system. Figure 9 shows the optimum proposed fuzzy logic controller which distributes the demanded power among the electric and hydraulic propulsion systems.

\section{Proposed System Simulation, Experiment, and Results}

The proposed model was simulated with MATLAB-Simulink. Figure 10 shows the main design subsystem. The vehicle parameters according to Table 2 were used in the simulation. The proposed hybrid simulation was compared with the conventional system. 


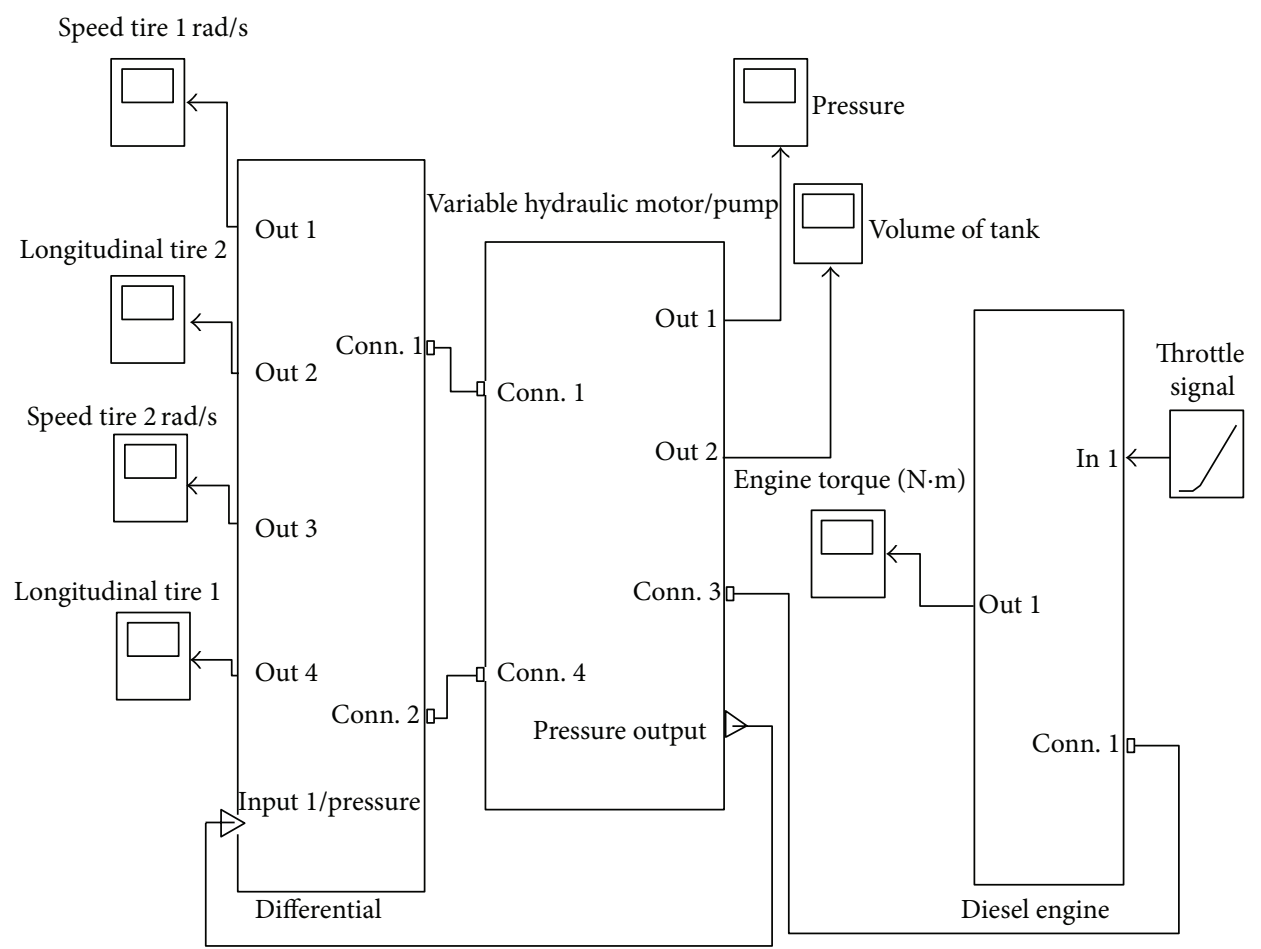

Figure 10: MATLAB-Simulink subsystem design.

TABLE 2: Vehicle parameters.

\begin{tabular}{lc}
\hline Diesel engine power & $120 \mathrm{KW}$ \\
DC motor/generator 2 power & $50 \mathrm{KW}$ \\
Hydraulic pump/motor power & $70 \mathrm{KW}$ \\
Vehicle weight & $15 \mathrm{Ton}$ \\
Accumulator size & $28 \mathrm{Lit}$ \\
Max battery power & $60 \mathrm{KW}$ \\
Differential ratio & 0.3 \\
\hline
\end{tabular}

The conventional system in Figure 2 contained a diesel engine which was connected to the differential and drive line through a gearbox. The results in Figure 11 indicated that the hybrid vehicle was faster than the conventional one with the same energy consumption. As a result it was also defined that the heavy vehicles with hybrid hydraulic/electric propulsion system were more efficient than the conventional systems.

The proposed system was also built up on a small vehicle to be tested. The simulation parameters were changed to the real small vehicle. Figure 12 shows the experimental model on a small hand-made vehicle. The vehicle was driven in two different types, first with full hydraulic propulsion without electric propulsion and next with full electric propulsion without hydraulic propulsion. The experiments have shown that the hydraulic propulsion system was more efficient and had better performances for low speed while higher torque was needed. On the other hand, the electric propulsion system was more efficient and had better performances while the vehicle was driven in higher speed with lower torques. In the study also speed comparisons were done

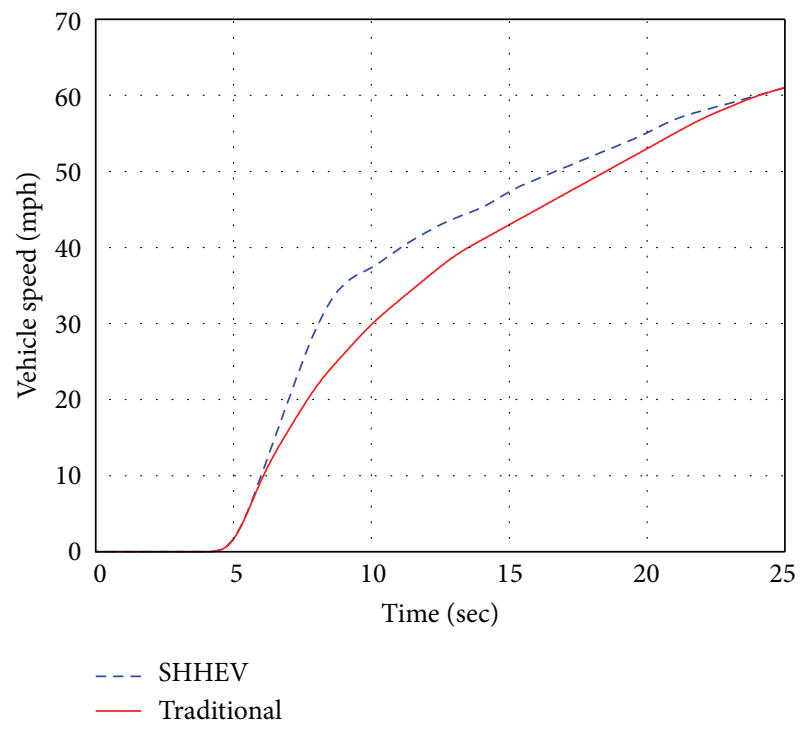

FIGURE 11: Conventional and hybrid comparison of acceleration time.

between the simulation and the experiments with the small model. Figure 13 shows the comparison and presents good agreement between the simulation and the experiments.

\section{Conclusions}

Hydraulic accumulator and battery system were designed as the energy storage sources for heavy hybrid vehicle to 


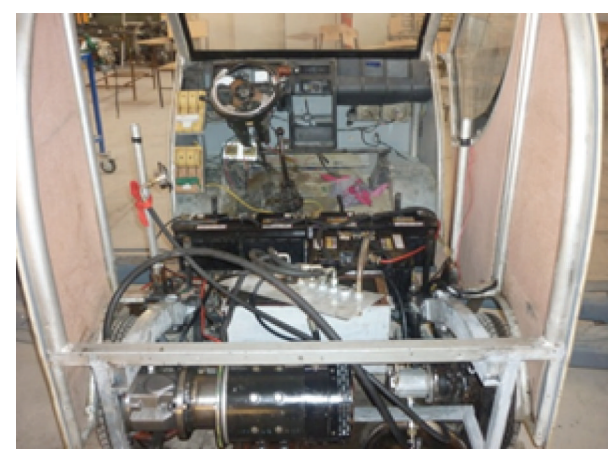

Figure 12: Hybrid hydraulic/electric experiment vehicle.

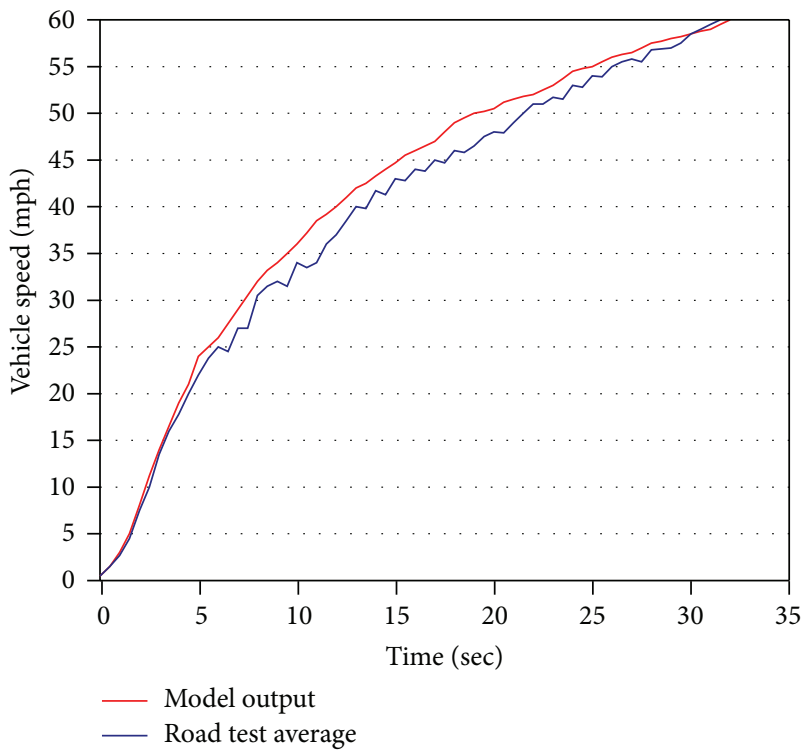

FIGURE 13: Simulation model and experiment acceleration comparison.

overcome the faults with using single energy sources. A fuzzy torque controller was introduced for presenting the simultaneous control of the electric and the hydraulic components, the demanded torque was distributed in the propulsion system to both sources and caused the minimization of the disadvantage of accumulator's lower energy density and battery's lower power density, and the hydraulic motor/pump and the DC motor/generator 2 effectively regenerate the braking energy and store it in accumulator and the battery for next usage. The hydraulic motor buffers the power load of battery to prolong battery lifespan. The diesel engine was adjusted in high efficiency regions as the power generation source. In this study a novel hybrid hydraulic/electric was simulated with MATLAB-Simulink and a small experimental model was built up too; the results have shown improvement in vehicle efficiency. The hybrid vehicle in comparison with the traditional vehicle could get more speed with the same energy usage. It shows better efficiency and cause fuel consumption reduction.

\section{Conflict of Interests}

The authors declare that there is no conflict of interests regarding the publication of this paper.

\section{Acknowledgments}

This proposed experiment was based on work performed within the Mechanic Research Center (MRC) supported by Islamic Azad University of Iran, commonly Takestan \& Shahr-e-Ghods branch.

\section{References}

[1] E. Karden, S. Ploumen, B. Fricke, T. Miller, and K. Snyder, "Energy storage devices for future hybrid electric vehicles," Journal of Power Sources, vol. 168, no. 1, pp. 2-11, 2007.

[2] A. W. Stienecker, T. Stuart, and C. Ashtiani, "An ultracapacitor circuit for reducing sulfation in lead acid batteries for mild hybrid electric vehicles," Journal of Power Sources, vol. 156, no. 2, pp. 755-762, 2006.

[3] A. Lynn, E. Smid, M. Eshraghi, and N. Caldwell, "Modeling hydraulic regenerative hybrid vehicles using AMESim and Matlab/Simulink," in Proceedings of the Enabling Technologies for Simulation Science IX, vol. 5805 of Proceedings of SPIE, pp. 2440, May 2005.

[4] Y. J. Kim, Integrated modeling and hardware-in-the-loop study for systematic evaluation of hydraulic hybrid propulsion options [Degree of Doctor of Philosophy], University of Michigan, Ann Arbor, Mich, USA, 2008.

[5] S. Hui, J. Ji-Hai, and W. Xin, "Torque control strategy for a parallel hydraulic hybrid vehicle," Journal of Terramechanics, vol. 46, no. 6, pp. 259-265, 2009.

[6] D. W. Tian, D. G. Xie, and S. M. Cui, "Hybrid energy control strategy for hybrid electric drive system in military vehicle," Journal of Mechanical Engineering, vol. 45, no. 2, pp. 41-47, 2009.

[7] H. Farzanehfard, D. S. Beyragh, and E. Adib, "A bidirectional soft switched ultracapacitor interface circuit for hybrid electric vehicles," Energy Conversion and Management, vol. 49, no. 12, pp. 3578-3584, 2008.

[8] P. Rodatz, G. Paganelli, A. Sciarretta, and L. Guzzella, "Optimal power management of an experimental fuel cell/supercapacitor-powered hybrid vehicle," Control Engineering Practice, vol. 13, no. 1, pp. 41-53, 2005.

[9] K.-R. Rydberg, "Energy efficient hydraulic hybrid drives”, in Proceedings of the 11th Scandinavian International Conference on Fluid Power (SICFP '09), Linköping, Sweden, June 2009.

[10] K. Popp and W. Schiehlen, Ground Vehicle Dynamics, Springer, Berlin, Germany, 2010.

[11] B. Wu, C.-C. Lin, Z. Filipi, H. Peng, and D. Assanis, "Optimization of power management strategies for a hydraulic hybrid medium truck," in Proceedings of the International Symposium on Advanced Vehicle Control (AVEC '02), pp. 1-6, Hiroshima, Japan, September 2002.

[12] B. Wu, C.-C. Lin, Z. Filipi, H. Peng, and D. Assanis, "Optimal power management for a hydraulic hybrid delivery truck," Vehicle System Dynamics, vol. 42, no. 1-2, pp. 23-40, 2004.

[13] K.-E. Rydberg, On performance optimization and digital control of hydrostatic drives for vehicle applications [Ph.D. thesis], Linköping University, Linköping, Sweden, 1983. 


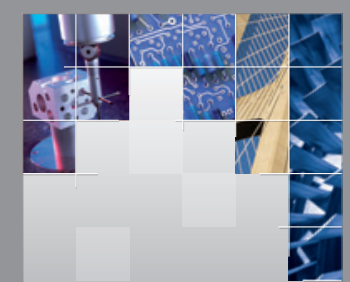

\section{Enfincering}
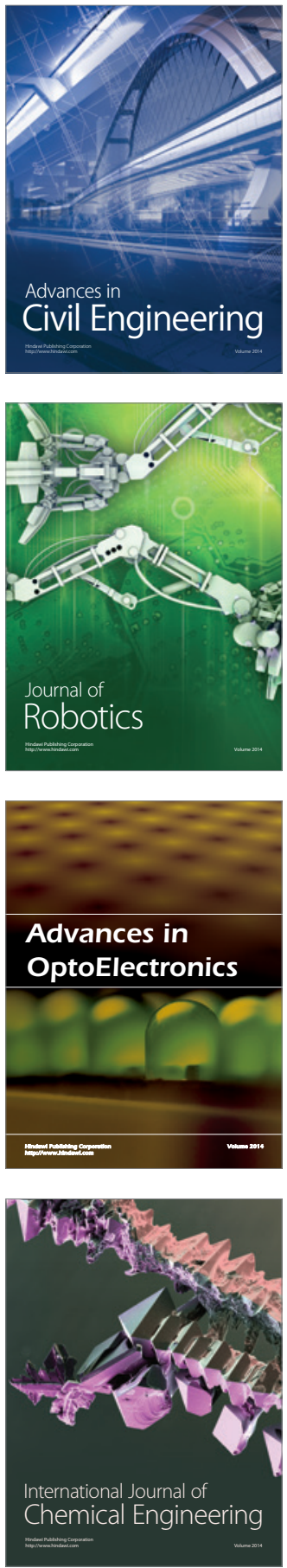

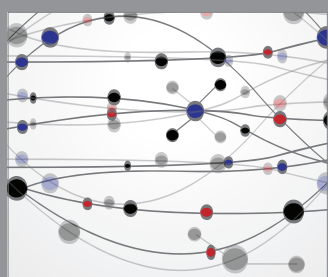

The Scientific World Journal

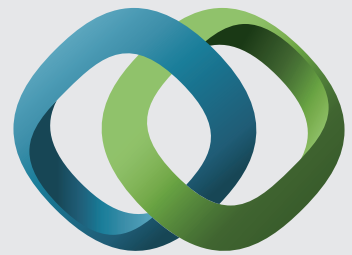

\section{Hindawi}

Submit your manuscripts at

http://www.hindawi.com
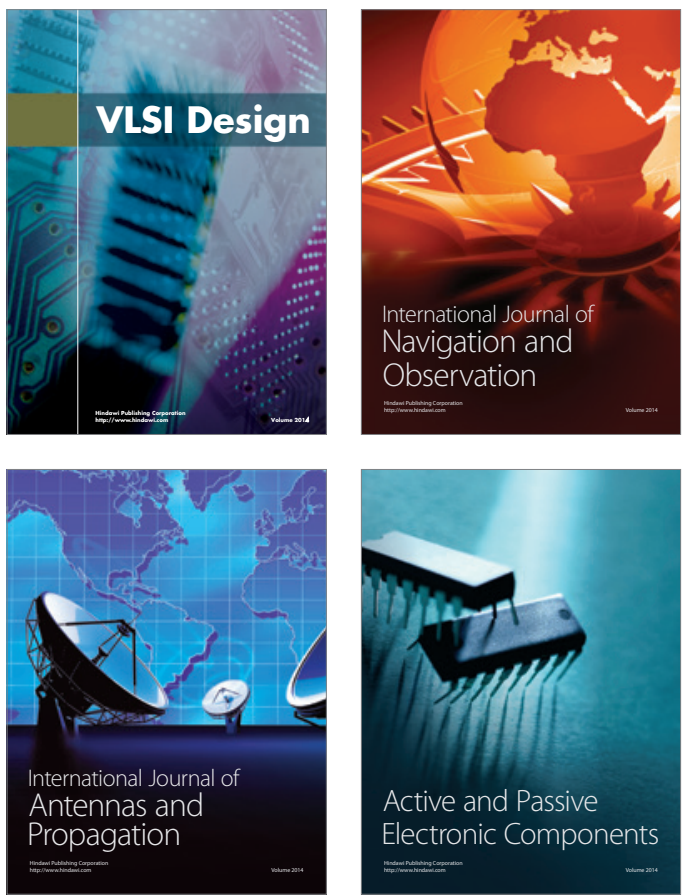
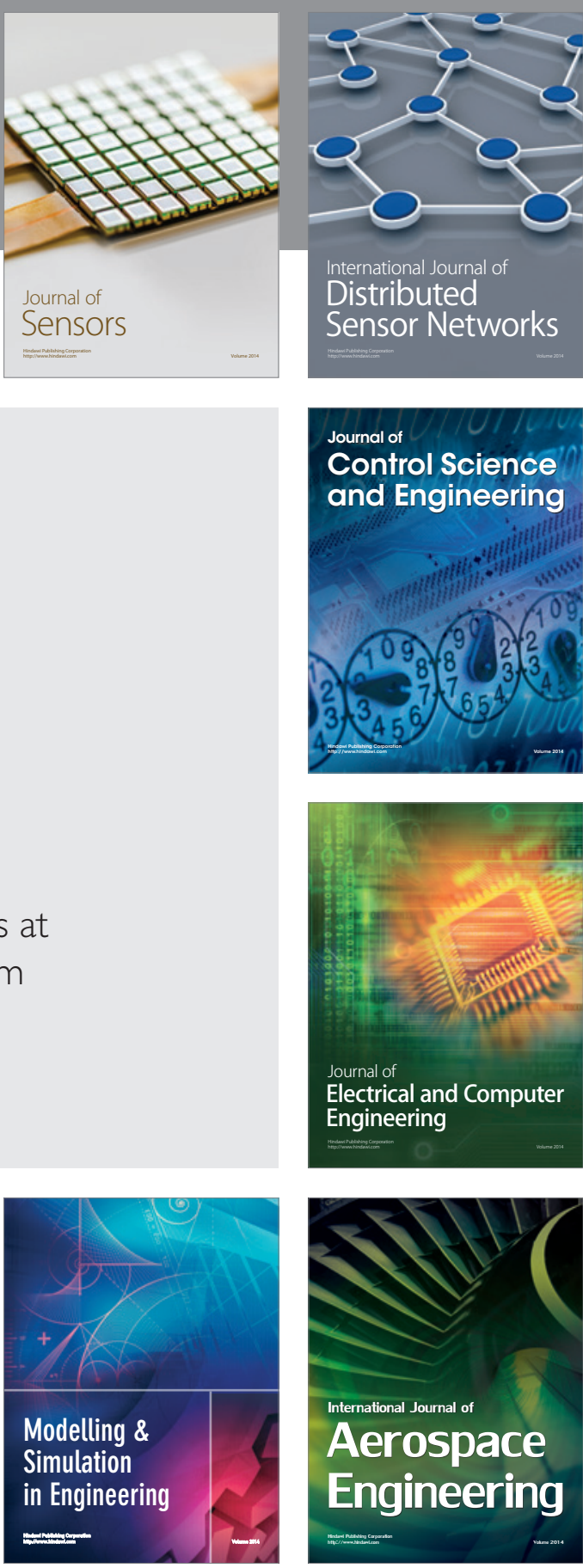

International Journal of

Distributed

Sensor Networks

Journal of

Control Science

and Engineering
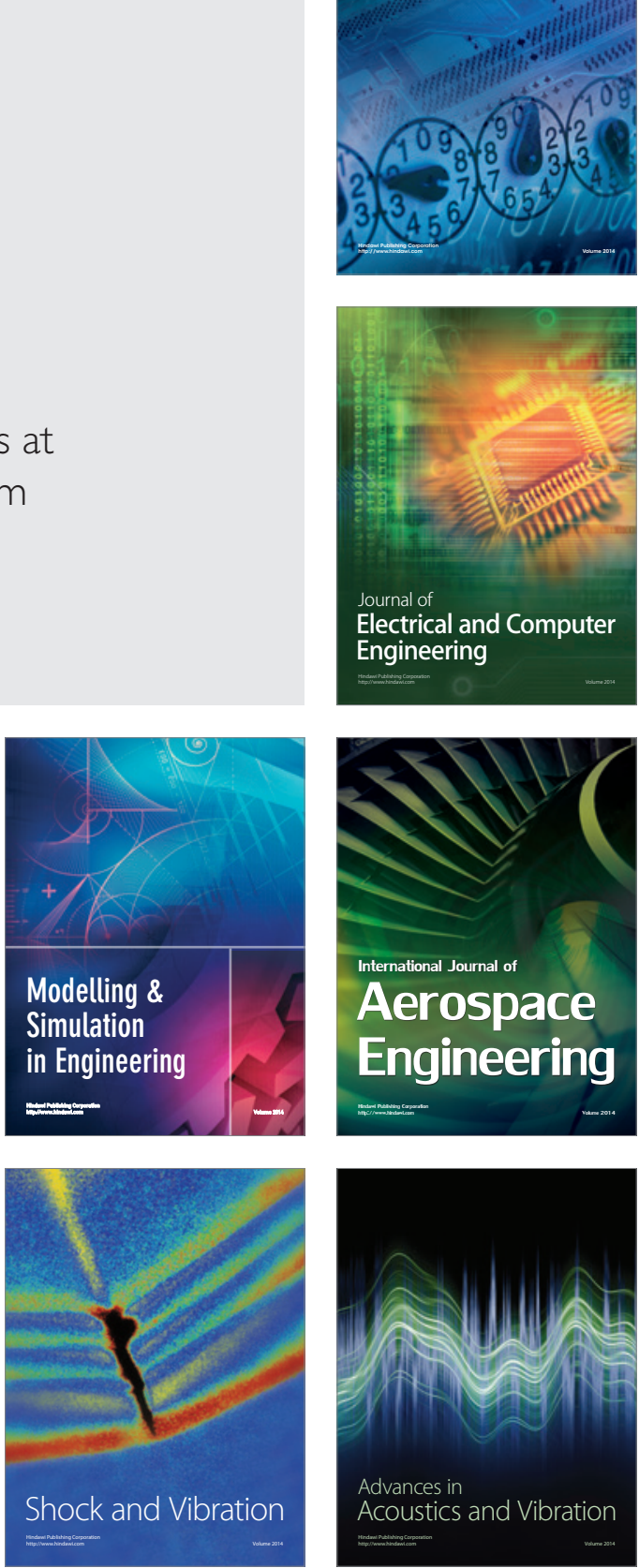